\title{
Effect of degree of cold work and annealing temperature on the microstructure and properties of cold drawn copper wires and tubes
}

\author{
S IVANOV, D MARKOVICH, L STUPAREVICH and \\ D GUSKOVICH \\ University of Belgrade, Technical faculty of Bor. 19210 Bor. Yugoslavia \\ MS received 21 January 1995; revised 15 July 1995
}

\begin{abstract}
tbstract. This work gives the results of influence of temperature and deformation degree on changes in the metal grain growth of drawn copper products, because this mutual dependence was observed. Wire samples of O.F.H.C. copper and copper tube samples, chemical content of $99.97 \% \mathrm{Cu}$ and $0.024 \% \mathrm{P}$, were exposed to recrystallized annealing after drawing. The annealing was carried out at temperatures of $400,450,500,550$ and $600^{\circ} \mathrm{C}$, for $30 \mathrm{~min}$. in laboratory conditions. Investigation results show that after drawing with high cold deformauon degree (96-99\%), the annealing leads to the changes in the continuous grain growth with increased temperature. The smaller grain size appears at $550^{\circ} \mathrm{C}$ in comparison with the lower annealing temperature. Annealing has influence on mechanical characteristics of tested samples and during drawing of copper products these characteristics are adequately changed: with regard to the annealing at the $500^{\prime} \mathrm{C}$, the characteristics of strength and plasticity increase is a result of decreased grain size. The increase of annealing temperature to $600^{\circ} \mathrm{C}$ leads to the increased grain size and decreased values of strength and plasticity characteristics.
\end{abstract}

Keywords. Degree of cold work; annealing temperature; grain size; cold drawn copper wire and tube.

\section{Introduction}

Many factors influence recrystallization kinetics and structure of recrystallized metal, as well as deformation degree, deformation rate, annealing temperature, annealing time, heating rate, starting grain size, existing impurities and secondary stages and others (Gorelik 1978). In some cases the increase of recrystallization temperature is associated with a certain texture formation (Bernshtein 1968).

In copper, due to the different texture formed after high degree of cold deformation, recrystallization temperature is considerably increased (Kolachev et al 1980). The structure of recrystallized metal depends on annealing temperature and texture. Consequently, recrystallized structure could not be anticipated, but it could only be experimentally established.

Keeping in mind the complex influence of deformation degree, annealing temperature and texture on recrystallization rate and also on recrystallized grain size and mechanical characteristics, the experiment with annealing temperature change on drawn copper products with high degree of deformation, was carried out in this work.

\section{Experimental}

OFHC copper wire and copper tubes, chemical content of $99.97 \% \mathrm{Cu}$ and $0.024 \% \mathrm{P}$, produced by high degree of deformation $(\varepsilon=96-99 \%)$ were used in the experiment.

Copper products, after drawing, were exposed to the recrystallization annealing at temperatures of $400,450,500,550$ and $600^{\circ} \mathrm{C}$, for $30 \mathrm{~min}$, in the laboratory 
conditions. The investigations include the testing of influence of deformation degree and annealing temperature on changes in the growth of recrystallizatized grain size and mechanical characteristics of drawing copper products, because this mutual dependence was observed. Metallographic investigations, mechanical investigations
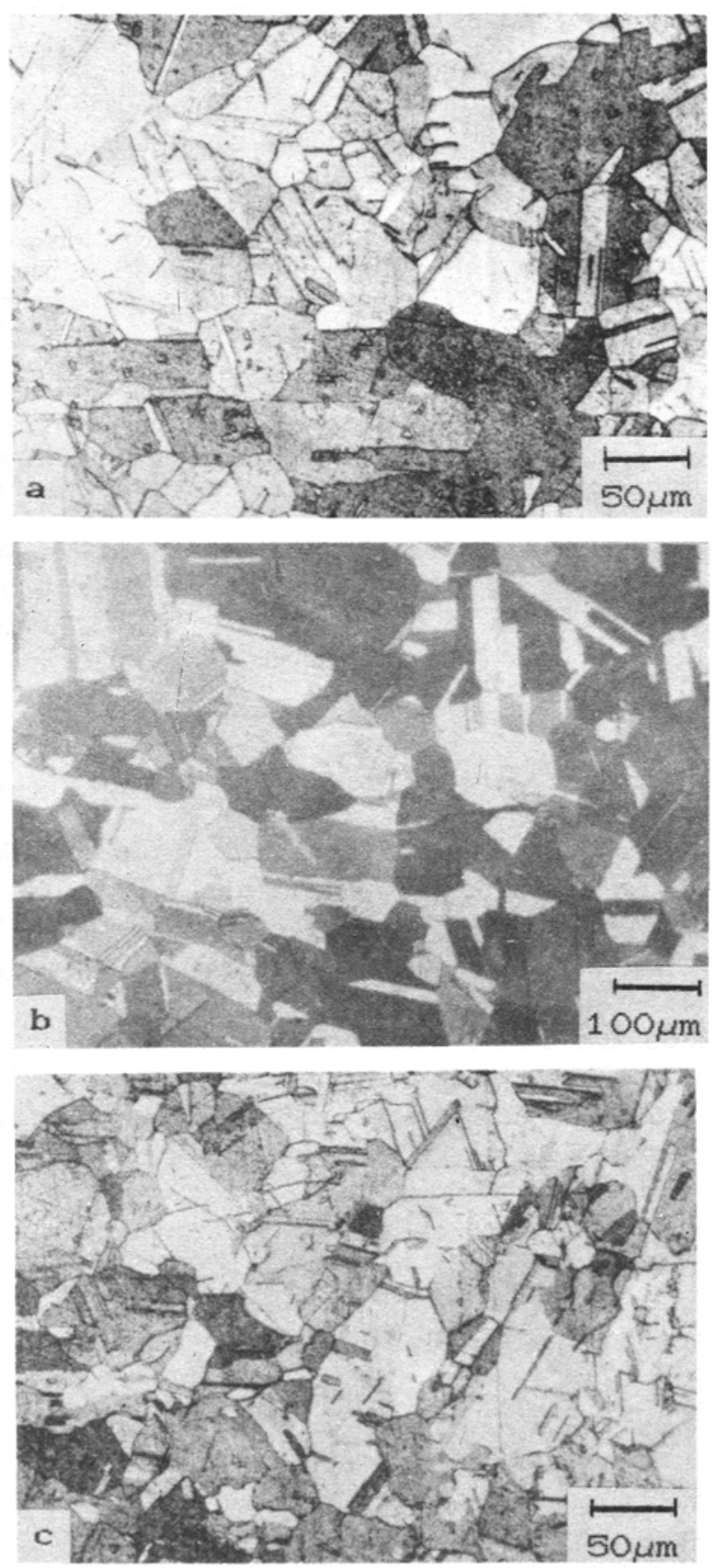

Figure 1. a-c. 

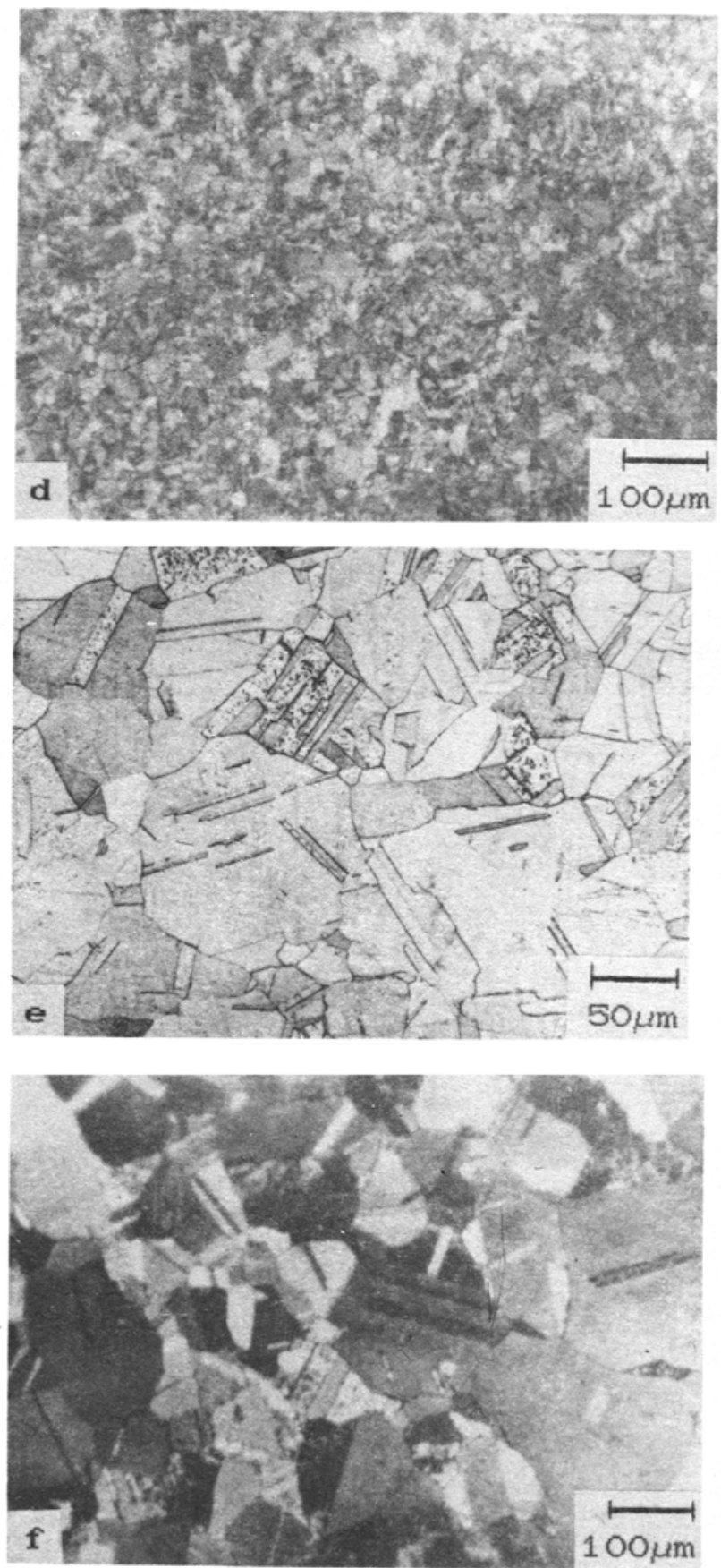

Figure 1. Microstructure of annealed drawn wire at (a) $500^{\circ} \mathrm{C}$, (c) $550^{\circ} \mathrm{C},(\mathrm{e}) 600{ }^{\circ} \mathrm{C}$ and annealed tube at (b) $500^{\circ} \mathrm{C}$, (d) $550^{\circ} \mathrm{C}$, (f) $600^{\circ} \mathrm{C}$.

(determination of tensile strength, hardness and elongations) and technological investigations (determination of spiral elongation number) were carried out on samples, to recognize the existing dependences after annealing. 


\section{Results}

Metallographic test on samples was carried out by optical microscopy. The structure of annealed samples show the polyhedrous recrystallized grains with clear twins. A method of comparable series by ASTM was used in this work for determination
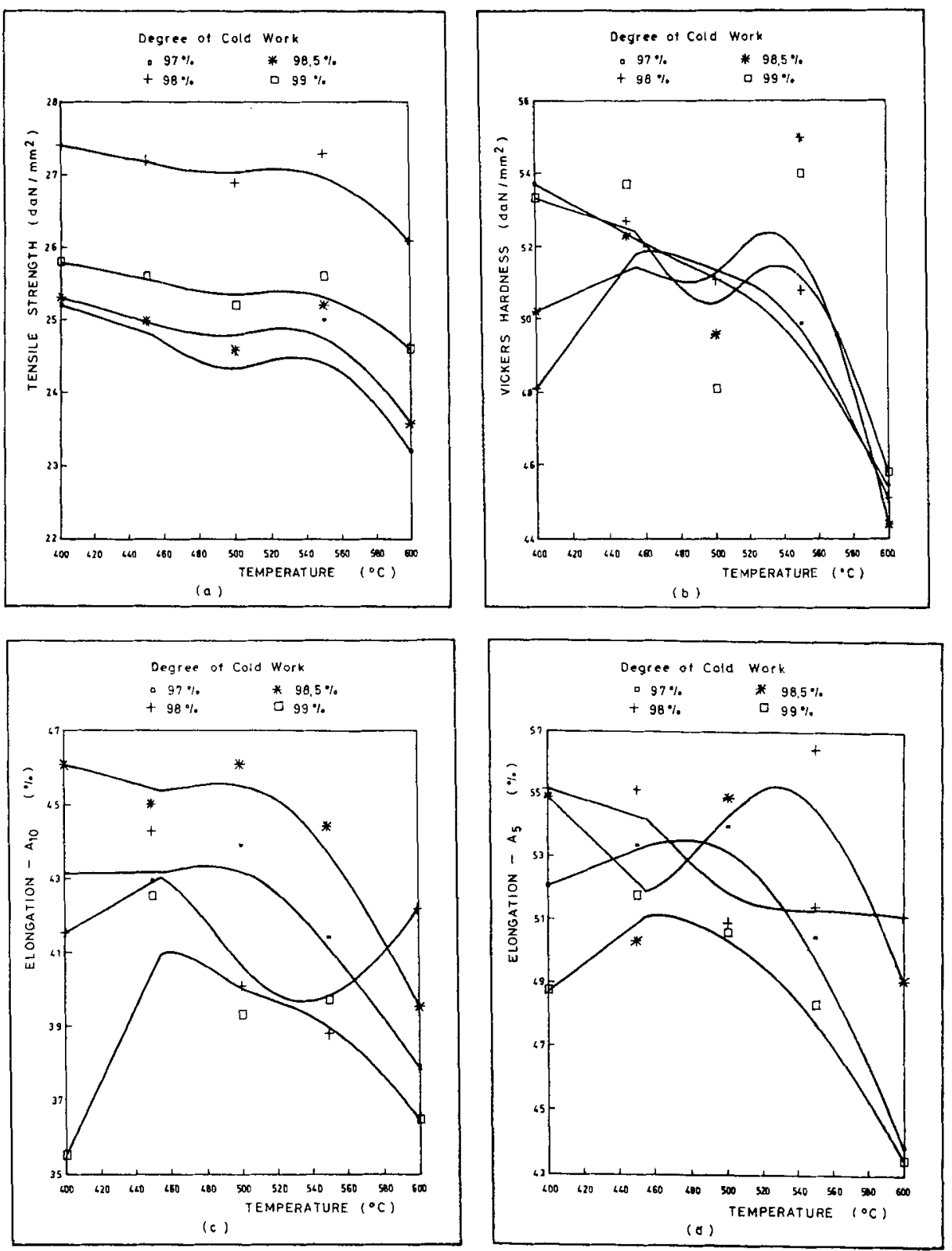

Figure 2. Dependence of mechanical characteristics of drawn copper tubes (a) Tensile strength - Rm, (b) Vickers hardness - $H V$, (c) elongation $-A_{10}$ and (d) elongation $-A_{5}$, with annealing temperature and degree of cold work. 
rabie 1. Appropriate equations for mechanical characteristics of tested samples.

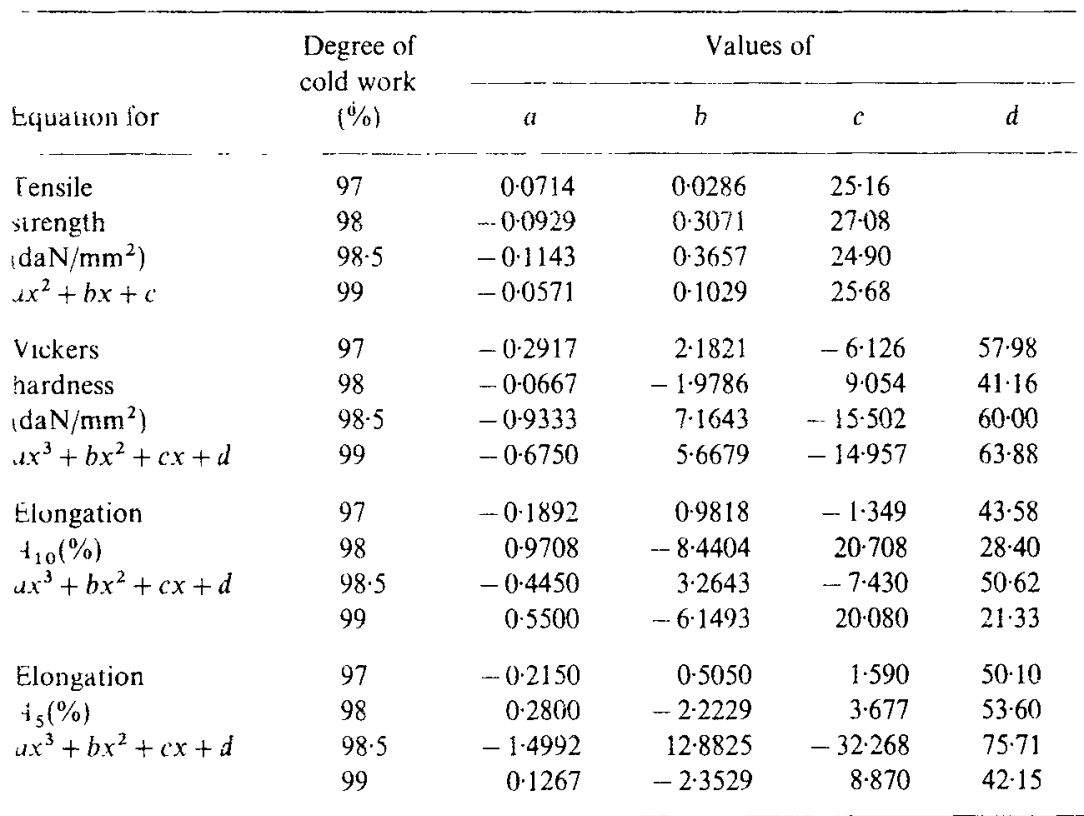

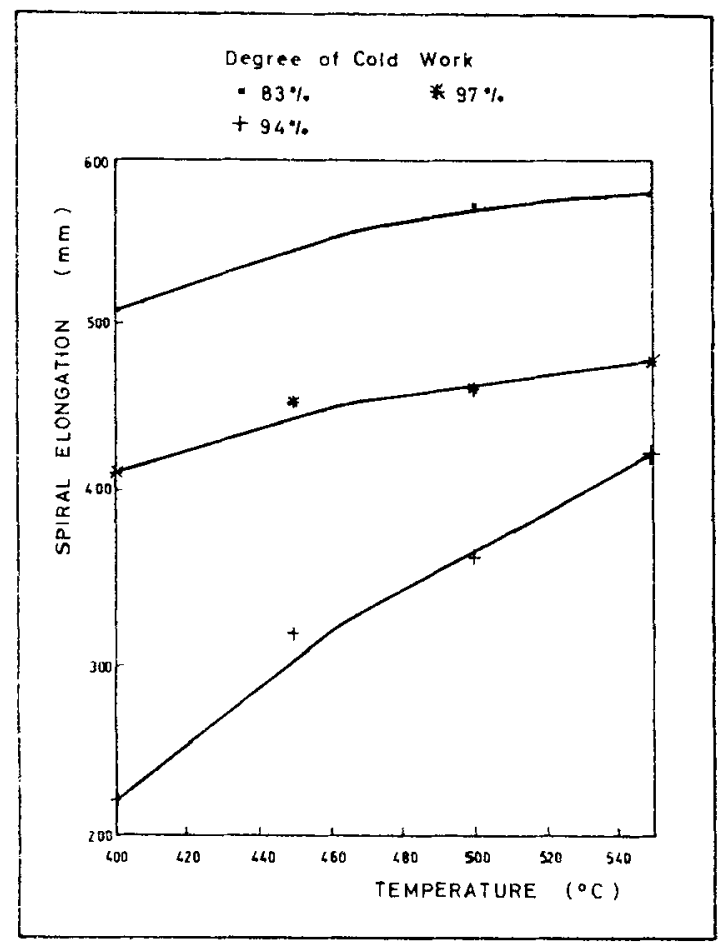

Figure 3. Dependence of spiral elongation number of copper wire on annealing temperature and degree of cold work. 
Table 2. Appropriate equation for the spiral elongation number of copper wire.

\begin{tabular}{|c|c|c|c|c|}
\hline \multirow[b]{2}{*}{ Equation for } & \multirow{2}{*}{$\begin{array}{l}\text { Degree of } \\
\text { cold work } \\
(\%)\end{array}$} & \multicolumn{3}{|c|}{ Values of } \\
\hline & & $a$ & $b$ & $c$ \\
\hline Spiral & 83 & $-8 \cdot 75$ & 67.45 & $450 \cdot 75$ \\
\hline elongation number & 94 & $-9 \cdot 50$ & $112 \cdot 10$ & $122 \cdot 00$ \\
\hline$a x^{2}+b x+c$ & 97 & $-6 \cdot 50$ & $53-70$ & 36500 \\
\hline
\end{tabular}

of metal grain size due to recrystallized structure of copper. The results show that the grain size increases with increase in annealing temperature. Especially, on samples obtained by drawing the high degree of cold deformation (96-99\%), the annealing changes the continuous growth of grain with increase in temperature. Considerable fine grained structure with regard to the lower annealing temperature, was observed on samples annealed at $550^{\circ} \mathrm{C}$, which is not a common phenomenon (figures 1c, d).

Further increase of annealing temperature results again in the grain growth. The details of characteristic sample microstructures after annealing at temperatures 500 , 550 and $600^{\circ} \mathrm{C}$ are presented in figure $1(\mathrm{a}-\mathrm{f})$.

The annealing also has influence on mechanical characteristics of tested samples. Figure 2(a-d) graphically presents the dependence of tensile strength $(R m)$, hardness $(H V)$ and elongation $\left(A_{10}\right.$ and $\left.A_{5}\right)$ of drawn copper tubes on annealing temperature after cold deformation $(\varepsilon)$. The functional dependence is represented also by appropriate equations (table 1).

The annealing temperature leads to decrease of tensile strength and hardness of the sample upto the temperature of $500^{\circ} \mathrm{C}$. As the result of decreased grain size on annealing at $550^{\circ} \mathrm{C}$ causes adequate changes in the mechanical characteristics of drawn copper tubes, the characteristics of strength and plasticity increases. Further increase of annealing temperature to $600^{\circ} \mathrm{C}$ results again in the decrease of strength and plasticity characteristics.

The degree of cold deformation before intermediate annealing (Vatrushin et al 1982) has great influence on characteristics and structure of drawn copper wire. High degree of cold deformation during final drawing $(97 \%)$ results in lower values of elongation and increased values of spring back. Spiral elongation number for these samples is also lower in comparison with final drawn samples by moderate degree of deformation $(83 \%)$. These results confirm high correlation degree between the copper wire characteristics (spring back and elongation) and spiral elongation number: with higher elongation and lower value of spring back of copper wire, the value of spiral elongation number is higher.

The existence of a correlation between spiral elongation number and characteristics of drawn copper wire (spring back and alongation) gives the possibility that by testing the first of above mentioned parameters one can get some data about the change of the other. The investigation results of spiral elongation number of copper wire after annealing at various temperatures are graphically presented in figure 3 .

The increase of annealing temperature results in continuous increase of spiral elongation number, and the following equation could be used for description of this dependence for different degrees of cold deformation: $a x^{2}+b x+c$ (table 2). 
However, the final samples drawn by high degree of deformation, at $550^{\circ} \mathrm{C}$ of annealing, have less spiral elongation number than samples drawn by moderate degree of deformation.

\section{Discussion}

The change in characteristics and structure, during the annealing of tested samples at temperatures upto $500^{\circ} \mathrm{C}$, is in accordance with common presentations on changes in the characteristics and structure of cold deformated metals during heating, as found in the general literature. The increased annealing temperature speeds up the recrystallization process and, during uniform annealing time, results in the continuous increase of recrystallized grain size (Bernshtein 1968; Lakhtin 1979).

The obtained investigation results are in accordance with general assumptions only for annealing temperatures upto $500^{\circ} \mathrm{C}$. The increased values of the characteristics of strength and plasticity is the result of fine grained structure during annealing at $550^{\circ} \mathrm{C}$.

The question now is what caused this effect of decreased value of recrystallized grain size.

To explain this phenomena, tests were carried out and it is necessary to keep in mind that the tests were carried out on samples which were cold deformated by high degrees of cold deformation before annealing. It is known that after high degree of cold deformation by drawing, the recrystallization temperature of copper is suddenly increased, due to the texture change of deformation (Kolachev et al 1980; Khidre and Ahmed 1981; Inakazu and Yamamoto 1983). On the other hand, according to the authors (Vatrushin et al 1982; Ivanov et al 1990, 1992), the various textures of recrystallization in copper wire, with regard to the texture of deformation, are obtained during the change of annealing temperature from $400^{\circ} \mathrm{C}$ to $600^{\circ} \mathrm{C}$. After annealing at $550^{\circ} \mathrm{C}$, there is the change of texture where recrystallization is slower, which has an influence on slow grain growth. Also, it could be expected that the same change of texture of recrystallization in drawn copper tubes would occur, during change of annealing temperature from $400^{\circ} \mathrm{C}$ and $600^{\circ} \mathrm{C}$, and this is the reason of fine grained recrystallized structure of tubes during annealing at $550^{\circ} \mathrm{C}$. After high degrees of cold deformation by drawing, the recrystallization temperature of copper increases due to the change of texture type of the deformed metal. So, a texture which causes slow recrystallization is formed during high plastic deformation. Starting from this, the fine grained structure in drawn copper products, during annealing in the range of tested temperatures $\left(400-600^{\circ} \mathrm{C}\right)$ is followed by change of texture.

\section{Conclusion}

Based on investigation results, it could be concluded that the texture has a great influence on characteristics of the drawn copper products, so the change of texture after annealing at $550^{\circ} \mathrm{C}$ could be of practical importance.

The increased annealing temperature in the range of $400^{\circ} \mathrm{C}$ to $500^{\circ} \mathrm{C}$ leads to the increase of recrystallized grain size and decrease in the characteristics of strength.

Annealing at temperature of $550^{\circ} \mathrm{C}$ leads to the fine grained recrystallized structure and evident increase in the characteristics of strength in comparison with annealing at $500^{\circ} \mathrm{C}$. 
The increase of annealing temperature to $600^{\circ} \mathrm{C}$ leads to the further increase of recrystallized grain size and decrease in the characteristics of strength.

\section{References}

Bernshtein M L 1968 Termomekhanicheskaya obrabotka metallov i splavov (Moskva: Metallurgiya) Tom 1 p. 212

Gorelik S S 1978 Rekristallizatsiya metallov i splatov (Moskva: Metallurgiya) p. 109

Inakazu N and Yamamoto H 1983 J. Jap. Inst. Metals 47266

Ivanov S, Stuparevich L, Markovich D and Guskovich D 1990 J. Mining \& Metall. 26167

Ivanov S, Stuparevich L, Markovich D and Guskovich D 1992 Fizika metallov i metallovedenie 787

Khidre F A and Ahmed N A 1981 Z. Kristallogr. 15783

Kolachev B A, Gabidulin P M and Piguzov J V 1980 Tekhnologiya termicheskoi obrabotki tsvetnykh metallov i splavov (Moskva: Metallurgiya) p. 178

Lakhtin J M 1979 Metallovedenie i termicheskaya obrabotka metallor (Moskva: Metallurgiya) p. 69

Vatrushin L S, Osintsev V G and Kozyrev A S 1982 Beskislorodnaya med (Moskva: Metallurgiya) p. 42 